\title{
Statistical characterization of brittle and semi-brittle fault rocks: a clast geometry approach
}

\author{
László Molnár • Tivadar M. Tóth • Félix Schubert
}

Received: 3 June 2014 / Accepted: 2 September 2014 / Published online: 13 September 2014

(C) Akadémiai Kiadó 2014

\begin{abstract}
In the present approach, clast geometric parameters-particle size distribution $(P S D)$, clast complexity $\left(D^{R}\right)$, aspect ratio $(A R)$, circularity (Circ), convexity (Conv) and clast orientation (Angle) — were examined in order to separate the diverse fault rock types (fault breccias, cataclasites and fault gouges), which typically own extremely different hydraulic and petrophysical properties. The available borecore samples were studied in a case of a thrust fault zone from the metamorphic basement of the Pannonian Basin, Hungary. Multivariate statistical methods were applied in order to find the geometric parameters that define the tectonites. The calculated discriminant functions emphasized the importance of the PSD, Angle, AR, and Circ parameters, in descending order. We defined proper combinations of geometric parameters which can clearly separate the fault rock groups, both pair-wise and jointly for the three groups. The discriminant functions also pointed out the relatively similar geometric features of fault breccias and cataclasites in contrast to the significantly different characteristics of fault gouges. The multidimensional scaling demonstrated a three-phase evolution of the analysed brittle tectonites, where the initial deformation is coupled with chaotic fabric giving a weakly disaggregated fault breccia texture. The transitional stage can be characterised by cataclastic flow, while in the most deformed fault gouge samples the strong fragmentation, clast-rounding and oriented texture dominate. These results possible provide constraints on the development and overall behaviour of the fault zone.
\end{abstract}

Keywords Brittle tectonites · Fault rocks · Petrograhic image analysis ·

Tectonite discrimination $\cdot$ Borecore data

L. Molnár $(\bowtie) \cdot$ T. M. Tóth · F. Schubert

Department of Mineralogy, Geochemistry and Petrology, University of Szeged,

Egyetem utca 2., Szeged 6722, Hungary

e-mail: molnar.laszlo@geo.u-szeged.hu

T. M. Tóth

e-mail: mtoth@geo.u-szeged.hu

F. Schubert

e-mail: schubert@geo.u-szeged.hu 


\section{Introduction}

\subsection{Brittle fault zones and their flow properties}

Intensively fractured basement reservoirs have an increasing role in water and hydrocarbon production worldwide (P'an 1982; Nelson 2001; Petford and McCaffrey 2003). In these fields, brittle fault zones play an important part in the hydrodynamics of the whole rock masses (Caine et al. 1996), as the upper crustal (down to $10-15 \mathrm{~km}$ depth) deformation structures can govern the local hydrodynamic-systems, by their barrier, conduit or combined behaviour (Antonellini and Aydin 1995; Caine et al. 1996; Evans et al. 1997; Billi et al. 2003; Storti et al. 2003; Manzocchi et al. 2010). In the past years, a large number of studies have realised the importance of these structures and addressed numerous papers for understanding the role of fault zones in hard-rock reservoirs.

The hydraulic character of a brittle fault zone-besides many other parameters (recent stress-field, cementation, dissolution, depth and water saturation (Wibberley and Shimamoto 2003; Faulkner et al. 2010 among others)) - primarily depends on the consisting tectonites, which are strongly affected by the interplay of their formation factors, like the protolith type, the degree of deformation, physical constraints of the paleostress field, and many others (Caine et al. 1996; Fossen et al. 2007; Manzocchi et al. 2010). The various types of fault rocks have extremely different flow-properties, thus governing diverse hydraulic regimes, even in the reservoir-scale.

Numerous studies have revealed that brittle displacement zones can be divided into two main structural elements (Caine et al. 1996; Lee and Kim 2005; Ben-Zion and Sammis 2003; Hausegger et al. 2010): first, the weakly disaggregated, densely fractured "damage zone" generally with highly elevated conductivity and permeability relative to the undeformed protolith; second is the strongly deformed and crushed fault core, where the pre-existing rock fabrics are erased by the fault development and replaced by fault rocks. This localised zone is the locus of the most of the accommodated displacement, coupled with a dramatic drop in the permeability, compared with the damage zone.

Weakly fragmented and comminuted, coarse-grained fault breccias are often observable in the fault core, adjacent to the damage zone. These have a slightly decreased permeability in comparison with the densely fractured damage zone, but a much higher permeability than the protolith and other parts of the fault core. For this reason, several authors regard these coarse breccia surfaces as the "boundary zone" (Wibberley and Shimamoto 2003; Billi et al. 2003).

The most important fault rocks in the fault core are usually cataclasite and fault gouge, which - due to the pervasive deformation-have suffered the strongest fragmentation (cataclastic deformation: "comminution", intensive clast rotation, "abrasion" and "chipping") (Sammis et al. 1986, 1987; Blenkinsop 1991; Storti and Balsamo 2010), and the planes of the most considerable displacements. Advanced failure can be observed in their welldeveloped internal microstructure, decreasing amount of clasts against matrix, cement and pore space and the loss of original internal cohesiveness, which also allows the classification between cataclasite and gouge. Generally, increasingly localised slip-planes evolve coupled with a dramatic permeability decrease in the fault core, as a result of a positive feedback between the intensive failure and fault-rock weakening. In total, cataclasite and fault gouge zones can be regarded as local, hydrodynamic barrier bands in reservoir-scale (Caine et al. 1996; Evans et al. 1997; Manzocchi et al. 2010).

The large-scale spatial interpretation of basement faults in the subsurface and their hydrodynamic parameters is problematic, as their appropriate geophysical characterisation is quite 
uncertain. As these tectonites resulted from the interplay of numerous, previously mentioned factors, it is a difficult challenge to find some, generally applicable geophysical parameters for identification of different segments of fault zones (Bistacchi et al. 2010; Jeppson et al. 2010). Structural extension can be more problematic, as it is a challenge to define the place of the core samples in the idealised fault zone in the lack of outcrop, and even more challenging to determine their extension according to 1D data. These facts increase the role and value of the core-samples, but, on the other hand, raise the necessity of a proper petrographical classification system for brittle fault rocks.

\subsection{Classification of tectonites and the key problems}

Aside from a few early attempts, the main petrographic classification systems of brittle tectonites are based on specific textural and microstructural properties, described by numerous studies (Sibson 1977, 1986; Chester et al. 1985; Sammis et al. 1986; Laznicka 1988; Tanaka 1992; Woodcock and Mort 2008). In these works, the following are the most frequent parameters: the ratio of visible clasts to matrix, cement, and pore space ("ratio of porphyroclasts", mainly volume per cent), the grain-size, and the "cohesiveness" of the samples (Table 1).

The influential works of Sibson $(1977,1986)$ stated that, in the classification of the fault rocks, clast ratio and size, cohesiveness and the development of foliations are the most important properties. Generally, the increasing deformation-due to its mechanism (fragmentation, abrasion, and comminution) results in a decrease in clast size and also in the ratio of clasts per area to matrix, pore-space, and cement. Woodcock and Mort (2008), according to the sedimentological usage, determined $2 \mathrm{~mm}$ as the grain size limit between coarse- and finegrained fault rocks, because if $30 \%$ of clasts are larger than $2 \mathrm{~mm}$ then the fault rock can be categorised as fault breccia, while the cataclasites are below that limit. A fault gouge is identified where only a few isolated clasts occur in the matrix (the optically visible amount of fragments is under 10\%) (Passchier and Trouw 2005).

However, the $2 \mathrm{~mm}$ clast size limit does not necessarily mean a change in the deformation mechanism, strengthening the statement that grain size is only a descriptive category, and there may be many more informative genetic factors, such as particle-size distribution (PSD)

Table 1 Classification of fault rock-series, adapted from Sibson (1977, 1986), Laznicka (1988), Tanaka (1992) and Woodcock and Mort (2008)

\begin{tabular}{lll}
\hline Criteria & Tectonite type & Grain size (mm) \\
\hline $\begin{array}{l}\text { Brittle fault rock classification } \\
\text { Incohesive }\end{array}$ & \\
\multicolumn{1}{l}{$\begin{array}{l}\text { Ratio of porphyroclasts (V/V \%) } \\
>30\end{array}$} & Fault breccia \\
$<30$ & Cataclasite & $<2$ \\
$<10$ & Fault gouge & $0.01-2$ \\
Cohesive & & $>0.01$ \\
Ratio of porphyroclasts (V/V \%) & \\
$>90$ & Protobreccia & $<5$ \\
$90-30$ & Breccia & $2-5$ \\
$<30$ & Protocataclasite & $0.1-2$ \\
$<30$ & Cataclasite & $0.001-0.1$ \\
$<10$ & Ultracataclasite & $>0.01$ \\
$<10$ & Pseudotachyllite & $>0.005$ \\
\hline
\end{tabular}


(Sammis et al. 1986; Blenkinsop 1991; Jébrak 1997); in contrast, grain size is only a simple tool for field interpretation of the fault rocks.

In numerous cases, the fault rocks may have retained some primary cohesion (Sibson 1977), for example as a result of the diffusive mass transfer and sub-critical fracture growth or obtained through the post-faulting processes, due to the precipitation of cementminerals from crustal fluids. The primarily incohesive fault rocks-defined by Brodie et al. (2007) as capable of being broken into component granules with finger-are mainly the result of shallow-depth deformation. However this fabric is quite often overprinted by the above mentioned precipitation, resulting in secondarily cemented structure (Woodcock and Mort 2008) and causing some difficulty in the definition of primary cohesion/incohesion. The proposed fault-rock scheme of Woodcock and Mort (2008) omits the cohesion as an important criterion, qualifying all coarse-grained fault rock as fault breccia. The only exception that can be regarded as incohesive is the fault gouge, although it is possible that incohesive structure is related to the weathering of the fine-grained cohesive fault rocks (Woodcock and Mort 2008).

Fault rocks, which tend to form by brittle shearing, have long been regarded as having only random fabric, without any structural indicators of the direction of the shear (Engelder 1974; Sibson 1977; Tanaka 1992). More recent papers (Chester et al. 1985; Cladouhos 1999; Wibberley and Shimamoto 2003) have proven that there are also observable shear indicators in brittle tectonites; however, in the weaker disaggregated breccias, a lack of any orientation is rather frequent, too.

Generally, the formation of cataclasites and fault gouges with foliations and asymmetric structures represents pervasive deformation at both the mesoscopic and microscopic scales (Chester et al. 1985), whose results resemble ductile shear and produce stretching lineations analogous to mylonites (Lin 1999), while the deformation is brittle. Numerous microstructural manners are able to determine the sense of shear; the most frequent indicators are microfaults, shear planes, (grain) shape-preferred orientation, inherited micas, and deformational bands (Passchier and Trouw 2005). Both granular and clay gouges usually show well-developed foliation in the surviving grains and the surrounding clay-rich matrix (Cladouhos 1999). However, care should be taken in the interpretation of the deformation indicators (especially in linear structures) (Tanaka 1992), as their fabric often shows only the last stage of the displacement history. The mentioned pseudo-ductile shear in rocks lacking cementation can dramatically lower the internal cohesiveness of strongly comminuted fault rocks.

Although there are numerous textural and microstructural parameters for the classification of brittle tectonites, in this study we attempt to analyse their geometric features and then compare the results with the earlier data in the literature.

\subsection{Main aim of the paper}

Earlier studies (Sammis et al. 1986, 1987; Blenkinsop 1991; Jébrak 1997; Bérubé and Jébrak 1999; Clark and James 2003; Billi et al. 2003; Storti et al. 2003; Billi and Storti 2004; Billi 2007; Mort and Woodcock 2008; Storti and Balsamo 2010) demonstrated a connection between some geometric parameters of fault rocks and their formation conditions, as different degrees and types of fragmentation processes induce definite changes in the clast geometry.

In this case, our measurements are based on geometric parameters of the clasts resulting from deformation, as numerous studies have examined their development in both natural and experimental conditions (Jébrak 1997; Keulen et al. 2007; Stünitz et al. 2010 among others). A wide set of these geometric parameters were analysed by the Petrographic Image Analysis (PIA) approach, where digitalised two-dimensional images of the samples (core samples 
at meso-scale and thin sections at micro-scale) are processed by a proper image analysis program.

This paper aims to define the most characteristic clast geometric parameters of different fault rock types, which were previously qualitatively classified by their microstructural features. As these tectonites have rather distinct hydraulic and petrophysical properties (porosity, permeability), the understanding of the main deformational mechanisms may promote a proper hydrogeological interpretation of the fault zones. The more accurate $1 \mathrm{D}$ extension of lithological information via the core to log the calibration of wells can be a further benefit of this method, especially in the case of re-evaluation of old wells (e.g. without borehole imaging).

Our classification attempt will be introduced through a case study on a basement fault zone from the Pannonian Basin; however the main focus of the paper is to reveal the geometric aspects of the distinct deformation mechanisms rather than to obtain some new results on the local geology.

\section{Applied methods}

\subsection{Description of petrographic image analysis}

Beyond the traditional microstructural analysis of the samples, which included the definition of the dominant fault rock types and lithologic composition of the clasts, digital image techniques were applied to determine the geometric characteristics of the particles. The Petrographic Image Analysis of meso- and micro-scale samples was used on their two dimensional pictures. Image processing of the bore-core samples was performed on core-scanner pictures (Fig. 1): samples with intact cylinder-shape could be scanned, resulting in photographs of their outstretched mantle. The photographs were taken by the ImaGeo core scanner in the Hungarian Geological and Geophysical Institute (Maros and Pásztor 2001), with a high resolution digital camera, using the highest possible quality $(0.075 \mathrm{~mm}$ pixel size $)$. The micro-scale analysis was achieved on micro-photographs from selected, structurally representative parts of thin sections, with constant magnification $(10 \times)$. In this case, clasts could not be segmented by the usage of a specific threshold tool as the matrix or cement was too heterogeneous, so the selection of edges was accomplished manually, one by one, using Corel Draw Graphic Suite X3. The clast geometric measurements were completed using the selected parameters in the open source ImageJ 1.48 .

\subsection{Measured parameters}

\subsubsection{Particle size distribution (PSD)}

Many solutions have been proposed for describing brittle tectonite particle size distribution $(P S D)$. As a consequence, some earlier studies (Sammis et al. 1986, 1987; Turcotte 1986) demonstrated the fractal character of the cumulative $P S D$, with the following equation: $N(s) \sim s^{-D s}$, where $N(s)$ is the number of particles smaller than a size $s$ (square root of the area (Blenkinsop 1991; Clark and James 2003)), while $D^{S}$ can be determined as the slope of the best fit line on a $\ln N(s)$ against $\ln s$ graph. Different $D^{S}$ values are expected for varying degrees of fragmentation process. 


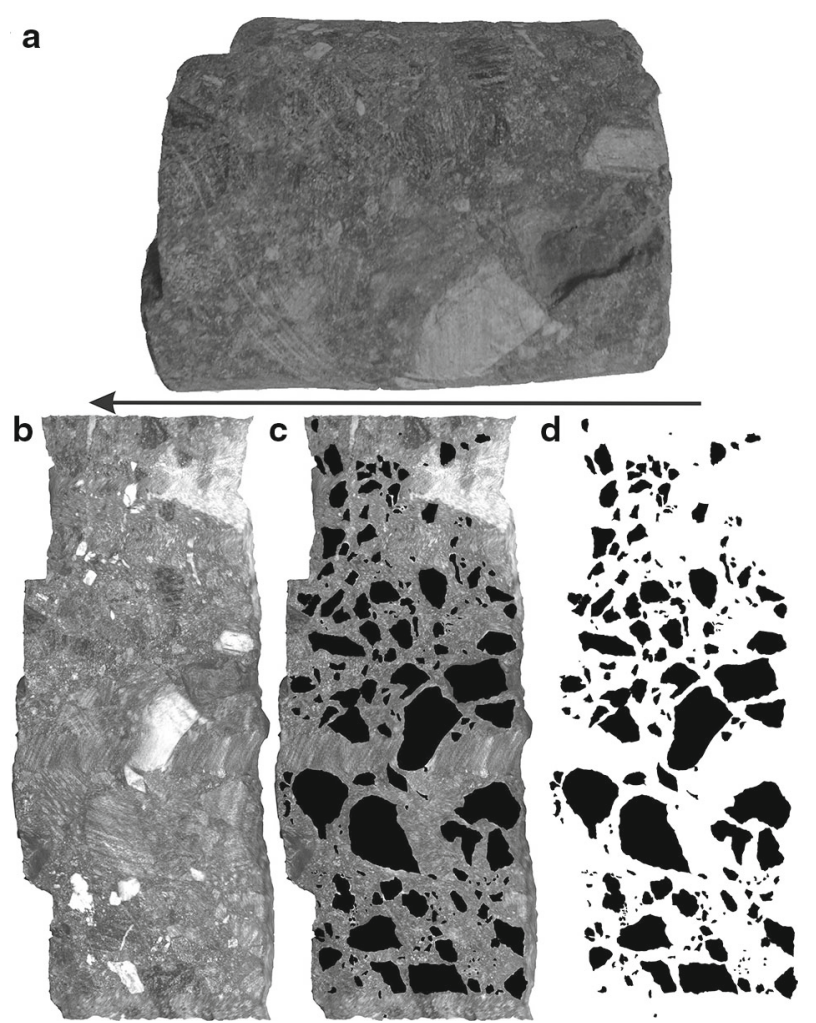

Fig. 1 a Core-sample from metamorphic basement of the Pannonian Basin. b Scanned core photo. c Clasts selected for the measurements, drawn one-by-one in Adobe Photoshop. d Separation of clasts from the matrix for the measurements in ImageJ. Arrows indicate the long axis orientation of the core

\subsubsection{Clast complexity $\left(D^{R}\right)$}

Several techniques can be used for the determination of clast complexity (structured walk, box counting, dilation, Euclidean distance mapping, etc.), from which, according to Bérubé and Jébrak (1999), the "Fractal Dilation" is the most precious method.

The "Fractal Dilation" macro of Image SXM uses a 1 pixel-wide outline of the clasts, which is later thickened by the macro, creating 2, 4, 8 and 16 pixel-width ribbons (Kaye 1989; Clark and James 2003). The area of these ribbons is plotted against its thickness on $\log -\log$ plot, resulting in a line with an $S$ slope, which is the indicator of clast-complexity fractal dimension $\left(D^{R}\right)$ using the $2-S=D^{R}$ equation (Kaye 1989).

\subsubsection{Aspect ratio $(A R)$}

The aspect ratio $(A R)$ is the proportion of the long and short axes of the ellipse that fits best to the clast's outline. The ellipse has the same area, long-axis orientation and centre as the original grain, defined by ImageJ. AR is a degree of elongation of the clasts affected by the tectonic deformation (Barnett 2004; Heilbronner and Keulen 2006). 


\subsubsection{Circularity (Circ)}

The value of circularity can be expressed by the equation of $4 \pi\left(A P / p^{2}\right)$, where $A P$ is the area of the clast, and $p$ is its perimeter (Barnett 2004; Mort and Woodcock 2008). This measures how close the particle's shape is to a perfect circle. According to the above formula, the value of the Circ varies between 0 and 1 , where 0 is an immensely elongated ellipse, while 1 is a perfect circle.

\subsubsection{Orientation angle (Angle)}

Shape preferred orientation (SPO), or grain shape preferred orientation (GSPO) (Passchier and Trouw 2005), of the brittle deformation-surviving grains (especially in the fault gouge) can show a preferred orientation (Tanaka 1992; Keulen et al. 2007). The numerical value of orientation for a single clast is the angle between the long-axis of the clast's best-fit ellipse and the lateral (the "X") axis of the image. In this case, our core samples were not oriented, so the possibly evolved orientation is only observable in the lowering of the dispersion from the average Angle values of the clasts, which is numerically manifested in the changes of relative standard deviation values.

\subsubsection{Convexity (Conv)}

Convexity measures the surface roughness of a particle, calculated by dividing the convex hull perimeter by the actual particle perimeter. Very smooth shapes have a Conv value close to 1 , while very spiky and irregular objects have a Conv value closer to 0 .

\subsection{Multivariate statistical methods}

Multivariate statistical methods (discriminant function analysis and multidimensionalscaling) were applied in order to answer the following questions: (1) how reliably can the fault rock types be distinguished based on their geometric parameters, (2) which parameters are responsible for characterisation of each group and (3) how do the different stages of deformation manifest in the measured PIA parameters. Discriminant function analyses were performed to define which parameters participate in the distinction of differ tectonite types, and to what level, both for pairwise and for all three groups. Discriminant functions were calculated with the forward stepwise method using Wilks' lambda. The probability of F-toenter was lower than 0.050 , the probability of F-to-remove was above 0.100 and the prior classification probabilities were equal for the lithologic groups. Discriminant functions were cross-validated to test the efficiency of the prediction model. The aim of multidimensionalscaling was to set the place of the samples in the theoretical six-dimensional space of the measured parameters. This method can illustrate the evolution of the particles from the aspect of geometric parameters and define which parameters can mark the different stages of deformation. The scree test of the multidimensional-scaling was also computed: the plot of the stress values against the different number of dimensions. The procedure is similar to the method of Cattell (1966), which was proposed originally for the factor analysis. IBM SPSS 20.0 Statistics was applied for the statistical evaluation of the results.

\section{Case-study: crystalline basement of the Pannonian Basin}

The above techniques and their application are introduced in a case study from a basement fault zone in the Pannonian Basin. The Variscan metamorphic basement of the Pannonian 


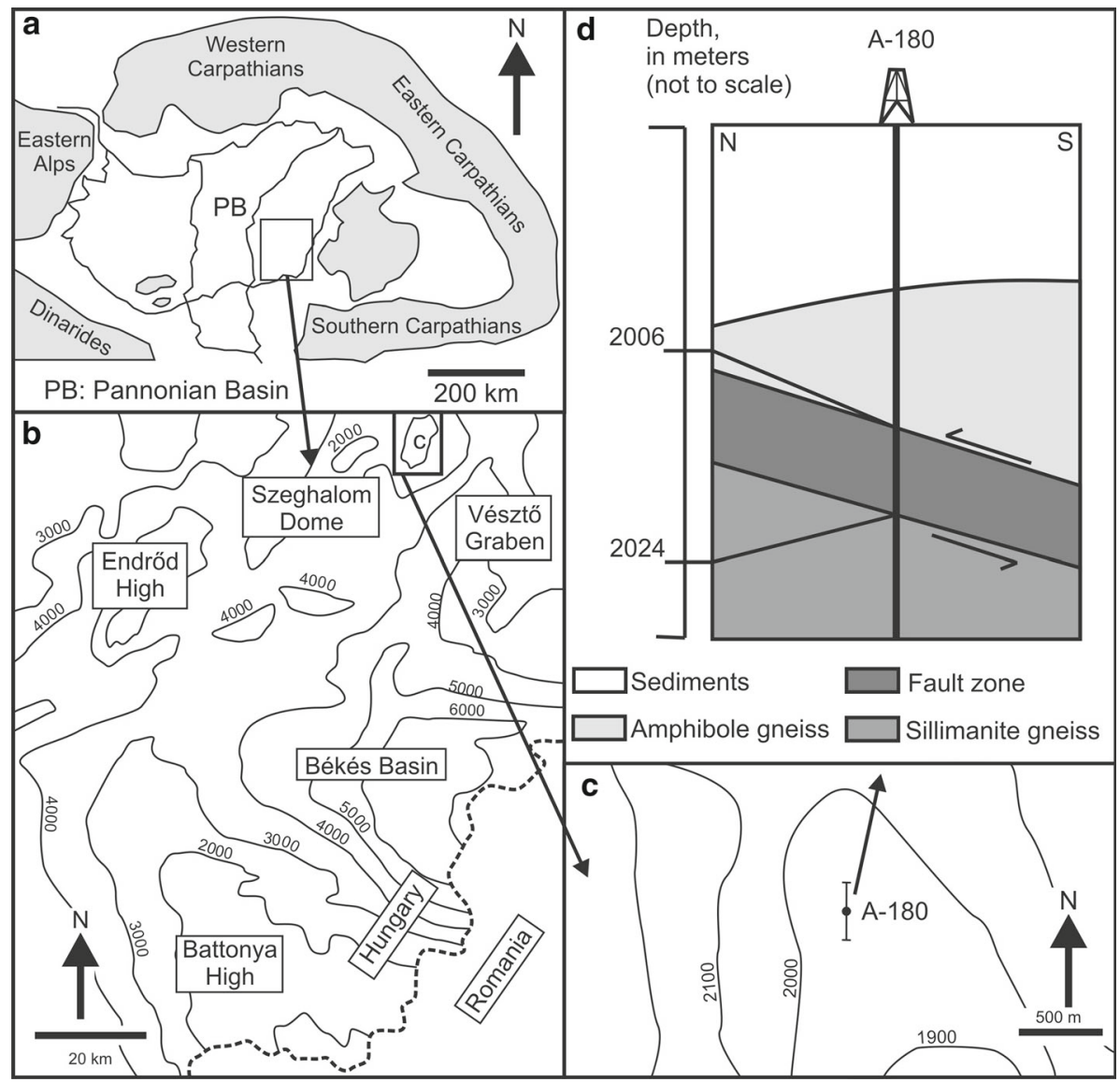

Fig. 2 Location of the Szeghalom Dome in the Pannonian Basin and their geological environment. The contoured map indicates the depth to the basement in meters. The figure (d) marks the depth interval of the investigated samples in a schematic north to south cross-section of the area

Basin is intensely fractured as a result of a complex post-metamorphic structural evolution and consists of numerous fractured hydrocarbon reservoirs, where the proper understanding of the fault zones is essential. One of the most important of these basement reservoirs is the crystalline Szeghalom Dome (Nelson 2001), which is mainly composed of gneisses of various metamorphic histories.

Szeghalom Dome lies in the northern margin of the Békés Basin, the largest sub-basin in the southern part of the Pannonian Basin, which is surrounded by elevated basement highs, such as the studied area (Fig. 2). The multi-stage tectonic evolution of the area resulted in a dense fracture network of the host rock body. Following the Variscan metamorphism, the most essential tectonic event was the Cretaceous compression of the Codru nappe system, which was proved by numerous earlier papers in the whole basement of the Pannonian Basin (Tari et al. 1999; Posgay et al. 1995). Moreover, the seismic interpretation on the Szeghalom Dome also indicated the presence of wide thrust zones throughout the crystalline high (Tóth et al. 2009). As a result, metamorphic blocks with rather distinct evolutions (Tóth 2008) were juxtaposed along these thrust surfaces, with amphibole gneiss on the hanging wall and sillimanite gneiss in the footwall. 
One of these major fault zones was penetrated by a well (A-180), situated north of the central and most elevated part of Szeghalom Dome, with close to $100 \%$ core recovery, making a detailed petrological investigation possible: 7 borecore (meso-scale sample) and 24 thin section (micro-scale sample) were involved in the evaluation. The examined section is approximately $20 \mathrm{~m}$ wide and quite heterogeneous petrographically. As the sampled fault zone-according to the palaeo-fluid investigations (Schubert et al. 2007) and the recent hydrocarbon production data - is the main migrational pathway inside the studied crystalline basement high, the classification of fault rocks with significantly different hydraulic properties is crucial.

\section{Results}

\subsection{Petrography}

Internal structure of the shear zone reflects strong diversity from petrographic aspects, consisting of different tectonites (breccia, cataclasite, foliated cataclasite, fault gouge). Most of the analysed meso- and micro-samples were composed of coarse fault breccia, with weakly disaggregated structures, and often with clast sizes over one mm-scale (Fig. 3a, b). Particles are slightly or not rotated, moreover a local mosaic, "jigsaw" texture can be observed, where the clasts are relatively easy to fit together along their sharp, angular dilation edges. The lack of any orientation and the random, chaotic structures are general in coarse fault breccia samples. These samples are clast-dominant, where the clast ratio is mainly over $30 \%$. Particles are dominantly composed of rock-fragments, derived from the wallrock, with recognisable gneiss protolith. Mineral fragments are subdominant in the coarse fault breccia samples.

On a few thin-sections, the manners of cataclastic deformation are observable (Fig. 3c, d). These specimens are usually embedded in breccia regions. Cataclasis resulted in decreasing clast size and increasing matrix/cement ratio. The possible appearance of local orientation is defined by the long-axis of the elongated clast, often coupled with deformed phyllosilicate flakes. These rock types reflect anastomising texture with local pseudo-ductile fabric as well. The protolith of the strongly deformed particles is locally hard to observe, they are often composed of only a single mineral phase (mainly quartz or feldspar).

Incohesive, granular gouge structures are observable only in thin deformational bands (Fig. 3e, f). These stages are the most crushed parts of the fault zone, which are mainly built up by extremely deformed mono-crystalline clasts. These isolated clasts are surrounded by the totally crushed parts of the protolith, also showing an anastomising structure, composing a "flow-banded" fabric. Most of the particles are single mineral grains; only a few survivor rock-fragments are observable. Gouge-bearing bands are always visible embedded in the foliated cataclasite bands. These few $\mathrm{cm}$ wide zones can mark "slip-zones" of the fault zones; these denote the places of the largest displacements.

According to the studied samples, in the fault zone in question, three main rock types can be distinguished based on their microstructural features:

- Coarse fault breccia (Group I)

- Cataclasite bands (Group II)

- Strongly deformed, thin gouge layers (Group III)

\subsection{Results of PIA}

The rather complex internal structure of the examined fault zone makes its geometric parameters suitable for comparison by PIA. The measured values for different tectonite types are 

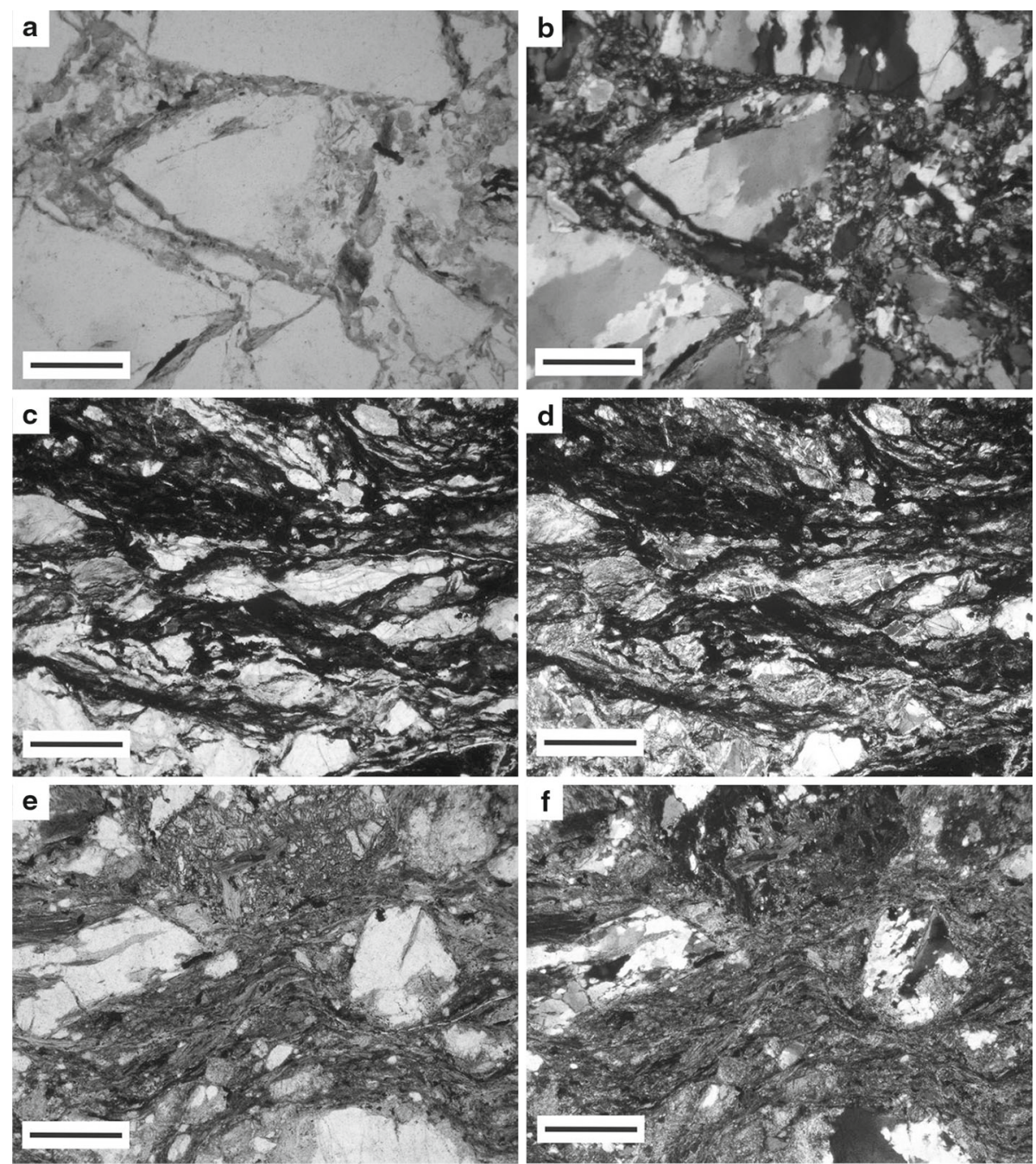

Fig. 3 a, b Coarse fault breccia, containing rock (gneiss) fragments (a in plane polarized light, b in crosspolarized light). c, d Oriented, elongated ribbons of clasts in foliated cataclastic fabric (c in plane polarized light, $\mathbf{d}$ in cross-polarized light). e, $\mathbf{f}$ Layers of comminuted gouge contains mainly crushed mono-crystals (e in plane polarized light, $\mathbf{f}$ in cross-polarized light). The scale bars are $500 \mu \mathrm{m}$

summarised in Fig. 4, where numbers of the samples indicate their order in the increasing fragmentation estimated from the microstructural observations.

The PSD fractal dimensions reflect significant, constant increases, both in micro- and meso-scale samples, as the texture becomes more disaggregated; this is in parallel with the petrographically-defined increasing deformation, $D^{S}$ dimensions also emerge (Fig. 4a). The intensively comminuted gouge-bearing zones have the highest $D^{S}$ results $(>1.7)$ and only the values of Group III samples exceed the theoretical value of $\sim 1.6$ for comminution and cataclasis (Biegel et al. 1989). 

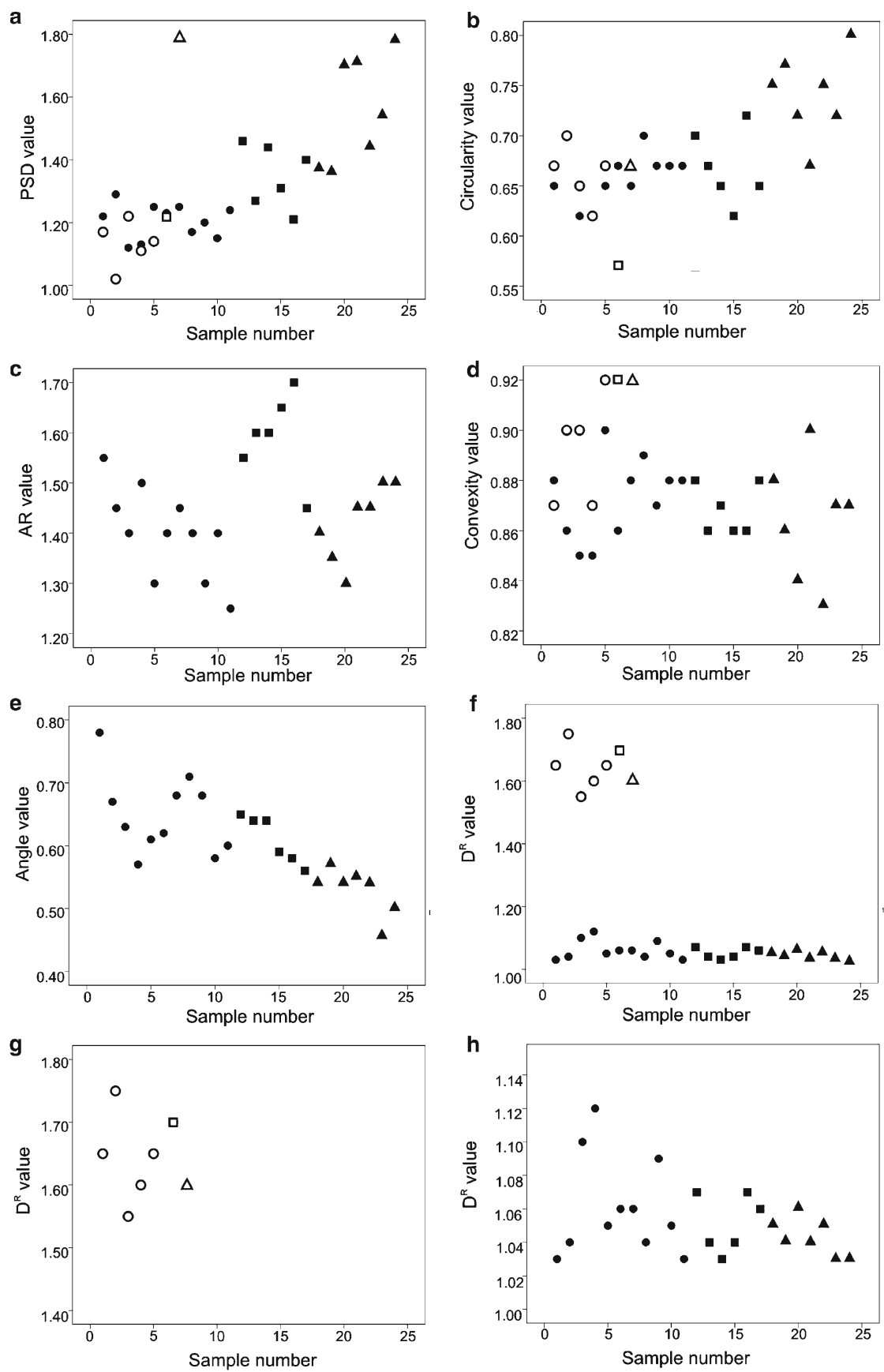

-/O : Fault Breccia (micro/meso scale) $\mathbf{\square} / \square$ : Cataclasite (micro/meso scale)

$\Delta / \Delta$ : Fault Gouge (micro/meso scale)

Fig. 4 Results of all geometric parameters. Samples are arranged in order of increasing disintegration. The degree of disintegration were estimated from the microstructural observations. The results of figure (f) are separated into figure $(\mathbf{g})$ and $(\mathbf{h})$, due to their strongly different values 


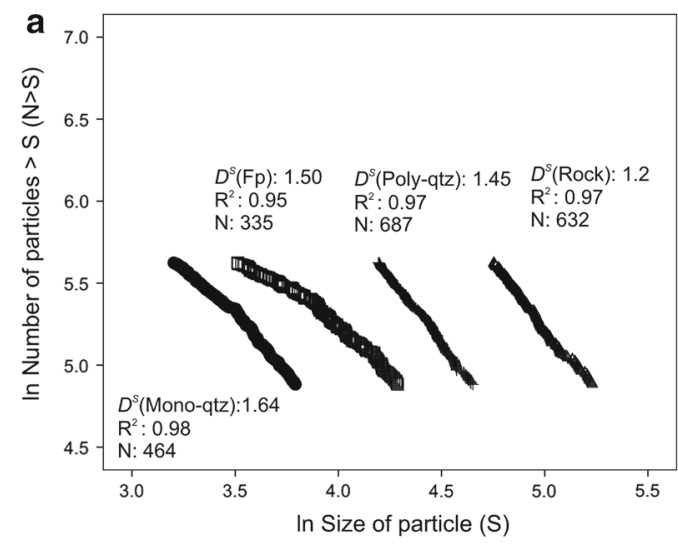

$\Delta$ Rock fragment

+ Polycrystalline quartz

口 Feldspar

- Monocrystalline quartz
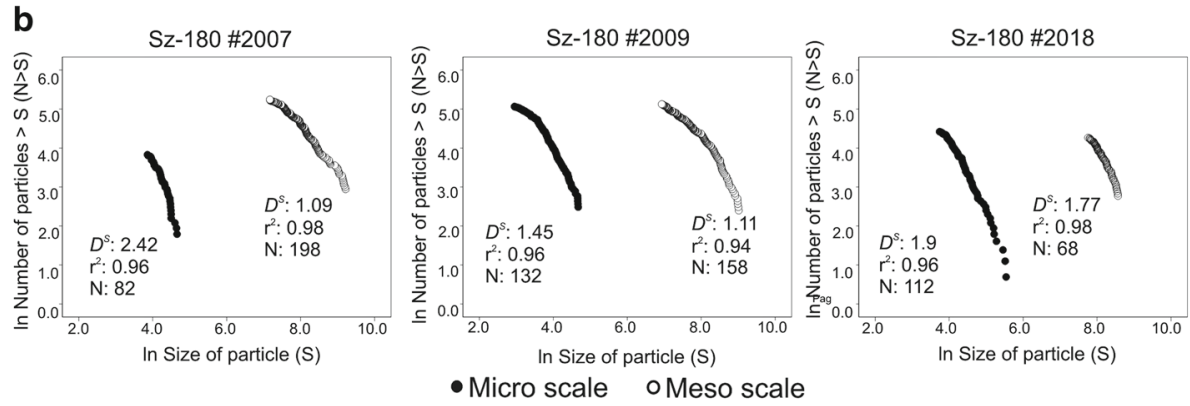

Fig. 5 a The $P S D$ values of different lithologies show rock fragments $\rightarrow$ polycrystalline quartz $\rightarrow$ feldspar $\rightarrow$ monocrystalline quartz order of fragmentation. Note: extreme grain sizes close to the lower and upper limit are neglected, as these clasts misfit at the scale of observation. b Comparison of PSD values of meso- and microscale samples from similar depth-interval. The micro-scale samples show constantly stronger fragmentation. Extreme grain sizes were also neglected in the measurement

From the aspect of clast material, the four main clast-lithology types (rock-fragments, feldspar, poly- and monocrystalline quartz, respectively) follow different $P S D$ values, in increasing order of rock-fragments, polycrystalline quartz, feldspar and finally monocrystalline quartz (Fig. 5a). In the comparison of the meso- and micro-scale PSD data, it is clearly visible that the meso-scale samples have constantly lower PSD dimensions than the microscale values from the same depth interval below the surface (Fig. 5b). The transitional gap from the upper size limit of micro-scale samples to the lower size limit of the meso-scale samples is always observed in the grain size range between 0.4 and $0.7 \mathrm{~mm}^{2}$ (Fig. $5 \mathrm{~b}$ ).

Circ values show a moderate increase in the Group III samples: all of these samples fall above 0.65 (Fig. 4b). The two less fragmented classes have smaller values without any other trends; results in both classes are in a narrow interval (in 0.6-0.7 Circ values), although the Group II samples reflect a slightly increased dispersion in their values.

There is no significant tendency in the values of $A R$ parallel with the observed deformation; only a moderate increase is visible in the results of Group II samples in comparison with other classes: all but one Group II sample have $A R$ values over 1.5 (Fig. 4c). In contrast, the Group I and III tectonites usually have $A R$ values lower than 1.5 (Fig. 4c). Meso-scale measurements of $A R$ cannot be applied, because of the geometric distortion derived from the scanned cylinder shape samples mantle, resulting in false major/minor axis ratios. 
No visible trend can be observed between the results of Conv and the different tectonites (Fig. 4d). Mode of convexity values are between 0.8 and 0.9 for every sample, both at microand meso-scales. The only remarkable characteristic is a relatively limited concentration of Group II values around $0.86-0.88$.

In contrast, there is a clear correlation between the degree of deformation and the clast orientation. Relative standard deviation of Group III samples yields lower Angle values $(\sim$ around 0.5$)$ than the other two classes, suggesting a more orientated texture with lower fluctuation in the direction of the clast's major axis (Fig. 4e). The SPO degree of core samples was not measured because of the misleading results derived from their cylinder-shape.

From the aspect of clast-complexity values (Fig. 4f), there is a strong difference between the core-sample and the thin section results. The first class has values that are constantly higher than 1.5 (Fig. 4g), while the latter group gives values that are always under 1.15 $D^{R}$ dimension (Fig. 4h). A moderate reduction is visible in the $D^{R}$ values parallel with the increasing observed deformation, especially in the Group III class.

\section{Discussion}

\subsection{Discrimination of tectonites based on geometric parameters}

Based on the results of the microstructural and PIA analysis of the samples multivariate statistical methods (discriminant function analysis and multidimensional-scaling) were applied. Only the micro-scale samples were involved into the evaluation, as this type of sample provided results from each of measured geometric parameter with a sufficient amount of particle (at least 50 per sample), following the instructions of Jébrak (1997) or Clark and James (2003) on the clast geometric analysis. The histograms of the frequency distributions for the variables revealed that the parameter values are normally distributed despite of their minor deviations (Fig. 6). The correlation and covariance matrices in the Fig. 7 reflect relatively homogeneous dataset, according to the results displayed in Table 2, especially in the diagonal plots, where correlations of the parameters were plotted against the covariances for each geometric feature.

In the discriminant function analysis, first-accepting the petrographic classificationthe tectonite types were compared pairwise to each other in the 6-dimensional space of the measured geometric factors to detach the distinct groups based on scores of the functions. The computation of the pairwise discriminant functions was necessary in order to define the main differencies between the microstructurally often strongly similar lithologic groups (fault breccias vs. cataclasites or cataclasites vs. fault gouges) and to reveal the possible similarities of the ungrouped sampes to the grouped samples via predictions. The groups (1: breccia, 2: cataclasite, 3: gouge) were separated by the following discriminant functions:

$$
\begin{aligned}
& \mathrm{D}(1,2)=1.168 * A R+0.996 * P S D-0.858 * \text { Angle } \\
& \mathrm{D}(2,3)=0.905 * A R-0.705 * \text { Circ }+0.642 * \text { Angle } \\
& \mathrm{D}(1,3)=0.698 * P S D+0.684 * \text { Circ }-0.506 * \text { Angle }
\end{aligned}
$$

The significance tests of the discriminant functions are displayed in the Table $3 \mathrm{a}, \mathrm{b}$ : all of the pairwise functions are significant and have a quite good correlation (D1,2: 0.929 D2,3: 0.891, D1,3: 0.924). To test their efficiency, the classification functions were cross-validated and these resulted in a relatively high accuracy (D1,2: 92.3 D2,3: 094.1, D1,3: $100 \%$ of 

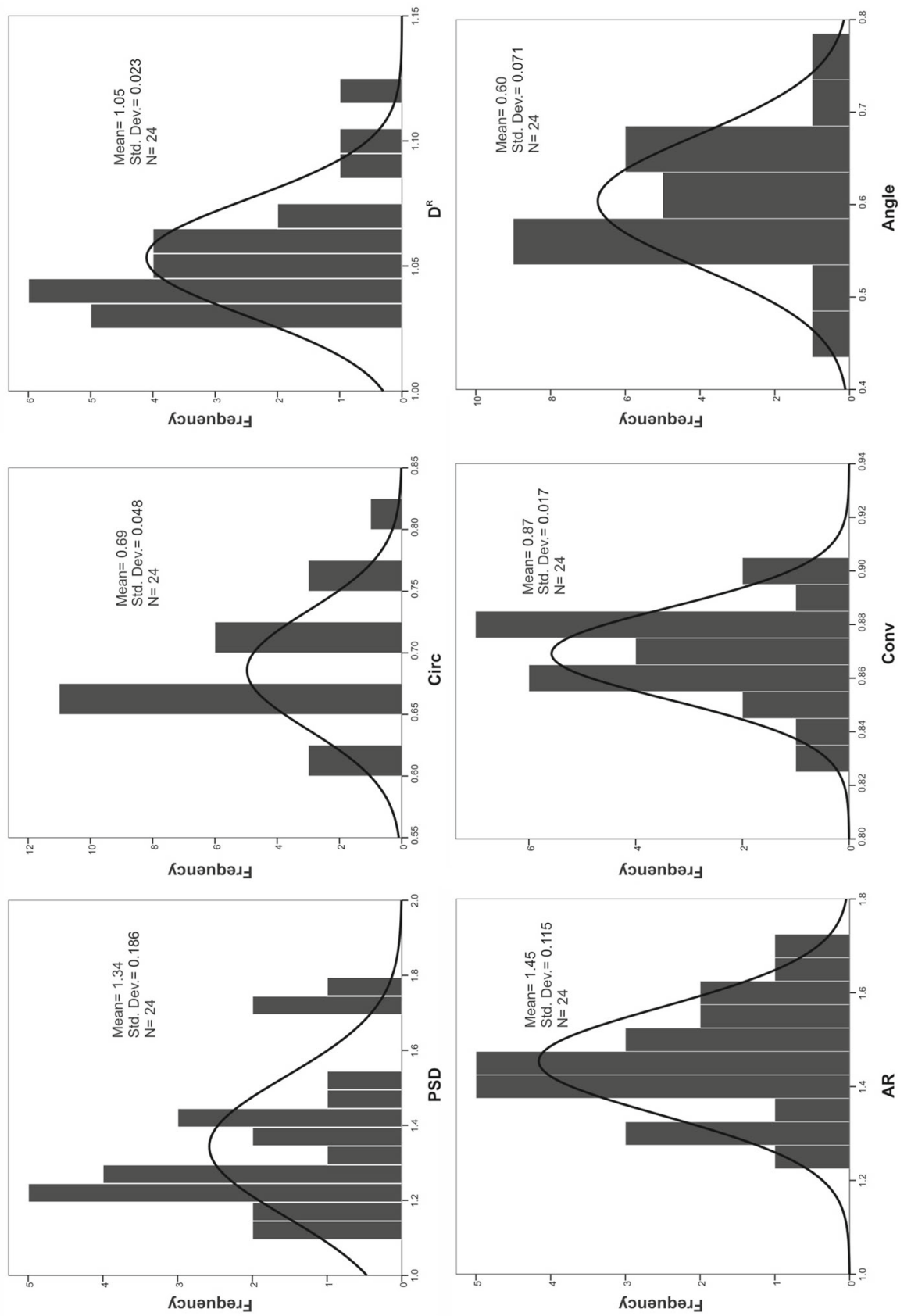

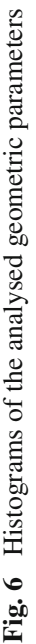




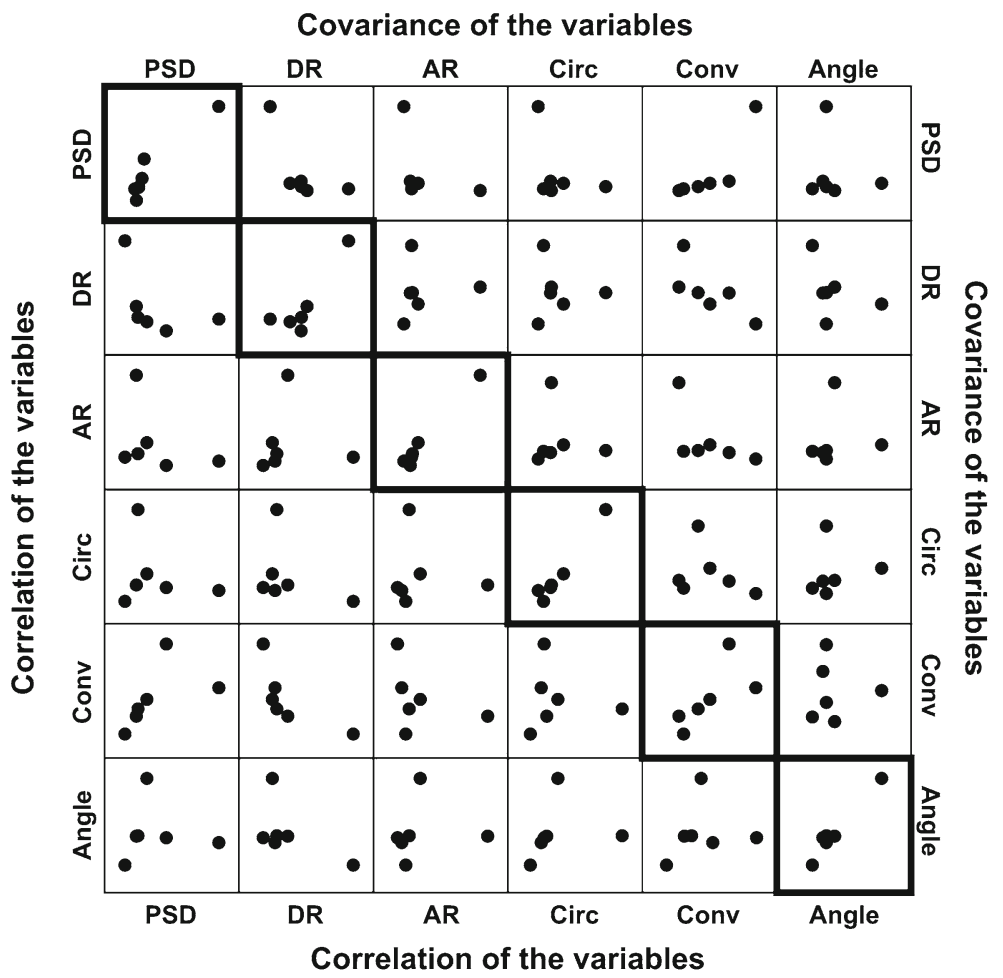

Fig. 7 Scatterplot matrix of the variable's data according to Table 2. In the lower part of the matrix the correlations of a variable with the other parameters are plotted against the similar data of other parameters. In the upper part, these are displayed in the case of the covariation. In the diagonal plots, the correlations and the covariances were plotted for each parameter

Table 2 Covariance and correlation matrices of the analysed geometric parameters

\begin{tabular}{|c|c|c|c|c|c|c|}
\hline & $P S D$ & $D^{R}$ & $A R$ & Circ & Conv & Angle \\
\hline \multicolumn{7}{|c|}{ Pooled within-groups matrices } \\
\hline \multicolumn{7}{|c|}{ Covariance } \\
\hline PSD & .01248 & -.00064 & -.00091 & -.00028 & .00059 & .00025 \\
\hline$D^{R}$ & -.00064 & .00053 & -.00009 & -.00017 & -.00018 & -.00034 \\
\hline$A R$ & -.00091 & -.00009 & .00721 & .00000 & -.00023 & .00061 \\
\hline Circ & -.00028 & -.00017 & .00000 & .00115 & -.00002 & .00025 \\
\hline Conv & .00059 & -.00018 & -.00023 & -.00002 & .00031 & .00010 \\
\hline Angle & .00025 & -.00034 & .00061 & .00025 & .00010 & .00260 \\
\hline \multicolumn{7}{|c|}{ Correlation } \\
\hline$P S D$ & 1.00000 & -.24772 & -.09617 & -.07490 & .30184 & .04397 \\
\hline$D^{R}$ & -.24772 & 1.00000 & -.04498 & -.21914 & -.43574 & -.29021 \\
\hline$A R$ & -.09617 & -.04498 & 1.00000 & -.00138 & -.15099 & .13979 \\
\hline Circ & -.07490 & -.21914 & -.00138 & 1.00000 & -.03549 & .14632 \\
\hline Conv & .30184 & -.43574 & -.15099 & -.03549 & 1.00000 & .11683 \\
\hline Angle & .04397 & -.29021 & .13979 & .14632 & .11683 & 1.00000 \\
\hline
\end{tabular}


Table 3 Details of the significance test for the discriminant functions with their roots (eigenvalues) and Wilks' lambdas for the pairwise functions (a) and D1-2 (b)

Pairwise functions

(a) Eigenvalues

\begin{tabular}{lllll}
\hline Function & Eigenvalue & \% of Variance & Cumulative \% & Canonical correlation \\
\hline D1,2 & $6.272^{1}$ & 100.0 & 100.0 & .929 \\
D1,3 & $5.840^{1}$ & 100.0 & 100.0 & .924 \\
D2,3 & $3.855^{1}$ & 100.0 & 1000 & .891 \\
\hline
\end{tabular}

(b) Wilks' lambda

\begin{tabular}{lllll}
\hline Test of function(s) & Wilks' lambda & Chi-square & $d f$ & Sig. \\
\hline D1,2 & .138 & 26.785 & 3 & .000 \\
D1,3 & .146 & 27.881 & 3 & .000 \\
D2,3 & .206 & 15.801 & 2 & .000 \\
\hline
\end{tabular}

D1-2 functions

(c) Eigenvalues

\begin{tabular}{lllcl}
\hline Function & Eigenvalue & $\%$ of Variance & Cumulative $\%$ & Canonical correlation \\
\hline 1 & $5.312^{2}$ & 82.7 & 82.7 & .917 \\
2 & $1.110^{2}$ & 17.3 & 100.0 & .725 \\
\hline
\end{tabular}

(d) Wilks' lambda

\begin{tabular}{lllll}
\hline Test of function(s) & Wilks lambda & Chi-square & $d f$ & Sig. \\
\hline 1 through 2 & .075 & 50.490 & 8 & .000 \\
2 & .474 & 14.563 & 3 & .002 \\
\hline
\end{tabular}

In D1-2 both of the functions add significantly to the classification (b)

${ }^{1}$ First 1 canonical discriminant functions were used in the analysis

2 First 2 canonical discriminant functions were used in the analysis

the samples were clasified correctly). In the pairs of groups, the following prediction can be made for the actually ungrouped samples (Fig. 8a):

$\mathrm{D}(1,2)$ : gouge is mainly grouped as cataclasite

$\mathrm{D}(2,3)$ : breccia is mainly grouped as cataclasite

$\mathrm{D}(1,3)$ : cataclasite is mainly grouped as breccia

These results indicate that cataclasites can be separated from the other two tectonite types mainly by their $A R$ values. In addition to this, the strong role of the Angle and PSD data in function $\mathrm{D}(1,2)$ emphasise their importance in differentiation between breccias and cataclasites, while the Circ values have high weight in the distinction of gouges from the other two groups. Angle data are participating in all of three discriminant functions, indicating their importance in the separation of tectonites with every degree of deformation. Beyond the obvious predictions of discriminant functions $\mathrm{D}(1,2)$ and $\mathrm{D}(2,3)$ (gouges are grouped as cataclasites, instead of breccias and breccias are grouped as cataclasites instead of gouges), the results of $\mathrm{D}(1,3)$ indicate that the cataclasites are generally more similar to breccias than to gouges. 
In the following, the three groups of tectonites were compared to each other by calculating the following D1-D2 discriminant functions (Fig. 8b):

$$
\begin{aligned}
& \mathrm{D} 1=0.731 * P S D-0.588 * \text { Angle }+0.553 * \text { Circ } \\
& \mathrm{D} 2=0.974 * A R+0.94 * P S D-0.271 * \text { Circ }
\end{aligned}
$$

According to the significance test of the D1-2 functions (Table 3c, d), both of the roots (the eigenvalues of the functions) add significantly to the classification. The larger proportion of the variance is related to D1 $(82.7 \%$, D2: $17.3 \%)$, and the functions have a fairly good canonical correlation (D1: 0.917, D2: 0.725). High prediction accuracy was obtained from cross-validation of the prediction model: $95.8 \%$ of the cases were classified correctly. In the D1 function, the PSD has the highest weight, followed by Angle and Circ values. As the D1 values remarkably increase in parallel with the petrographically observed deformation, this indicates that these parameters are the markers of the degree of deformation, while the three other factors $\left(D^{R}, C o n v, A R\right)$ have subordinate roles. This also means that the measured $P S D$ dimensions reflect a connection with the observed deformation, in accordance with the results of earlier authors (Sammis et al. 1986, 1987, Blenkinsop 1991; Storti and Balsamo 2010), who pointed out that the increasing deformation manifests in an increasing number of relatively smaller particles, which results in a higher $D^{S}$ dimension.

In connection with the role of $P S D$ values, it is important to reveal the relationship between the two measured scales. From the aspect of comparison of mechanical behaviour of the meso- and micro-scale samples, there is a strong difference according to the fragmental properties by the $P S D$ values. The significantly lower $D^{S}$ values of core samples can be the result of the weaker deformation, while the high values of micro-scale samples suggest strong fragmentation. The values considering macro- and micro-scale representing the same depth interval show an abrupt change in the tendency of $P S D$ values, between grain sizes of 0.4 and $0.7 \mathrm{~mm}^{2}$, suggesting a mechanism change. This could be in connection with the entrance of single-mineral phases, as the particle size reduction reached the level of micro-scale clasts. The PSD values imply the mechanical strength of the particles in the order of rock fragments $\rightarrow$ polycrystalline quartz $\rightarrow$ feldspar $\rightarrow$ monocrystalline quartz. These results, with the abundance of monocrystalline quartz grains in the most deformed fault gouge samples, coincide with the earlier studies regarding the strength of quartz particles (Heilbronner and Keulen 2006).

The parameter Circ also has a high weight with regard to D1 function, implying that its values increase in parallel with the progressive deformation. The evolution of higher Circ values in the intensely deformed samples can be the result of the gouge formation, which was strengthened by numerous earlier papers (Engelder 1974; Storti et al. 2007; Storti and Balsamo 2010); chipping, rounding and abrasion result in a more circular outline on the clasts in the fault gouges. All of these processes abrade the sharpest parts of the grain boundaries due to the intensive particle interactions.

The Angle values have strong negative weight in the D1 function. This implies that the developing orientation (the decreasing relative standard deviation of the long-axis angle values) evolves in parallel with the increasing deformation, as the previous, chaotic structure is replaced by a more oriented fabric. This implies that the angles of particle's long axes have lower scattering, by accepting the statement that the long axes reflects the orientation of a single clast, according to the evolution Grain Shape-preferred Orientation (GSPO) (Cladouhos 1999).

The discriminant function D2 is strongly determined by the $A R$ and-just like in D1$P S D$ values, while the Circ has a lower role; in contrast, the other three $\left(D^{R}\right.$, Conv, Angle $)$ 

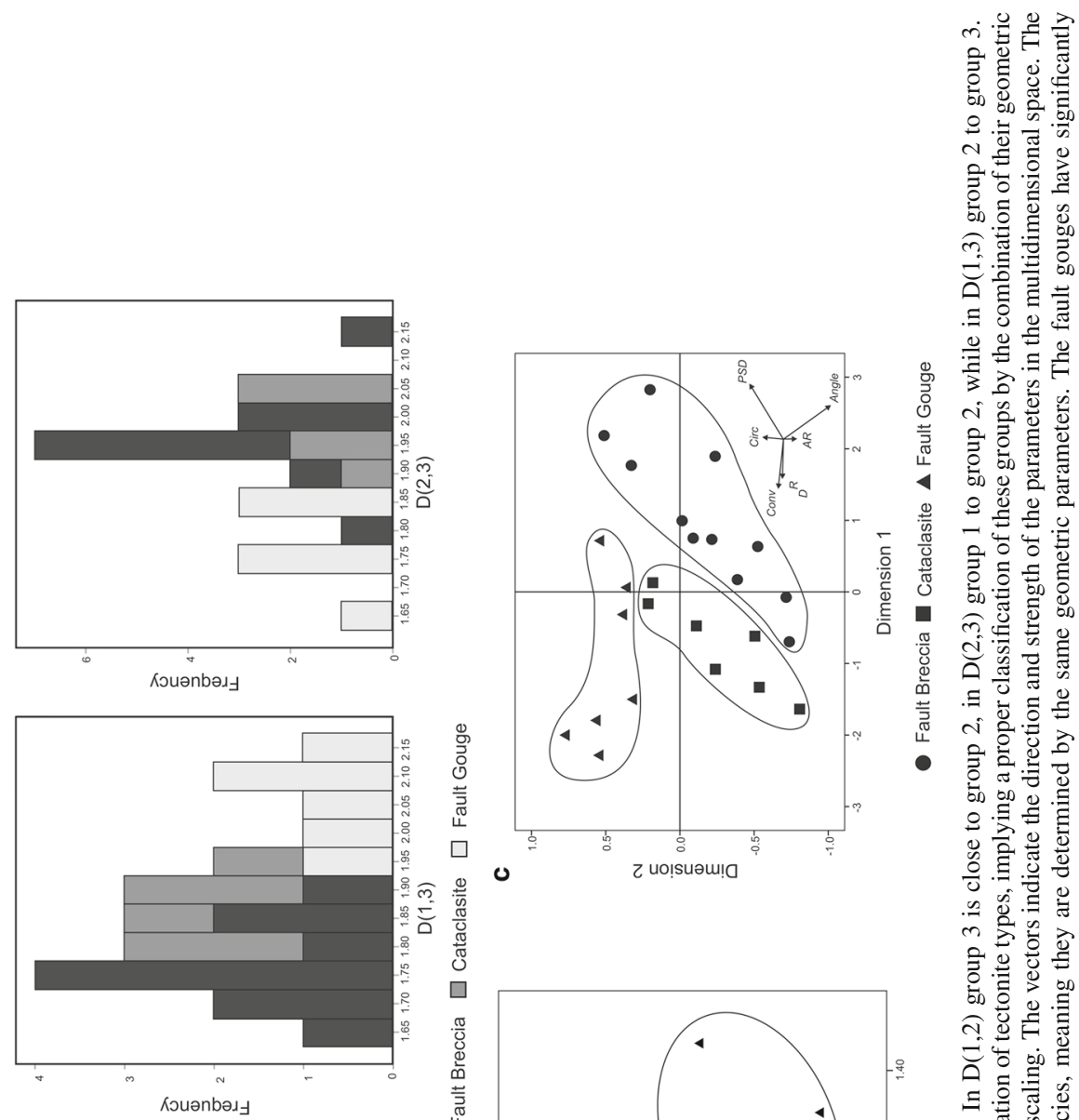

$\stackrel{0}{=} \cong$

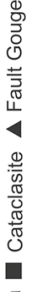

i के

응 巳

कू का

क \& 2 \&

$\stackrel{\Xi}{\Xi} \cong$

$\because$ 눙

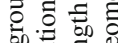

(ก)

กิ

กั: Е

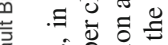

늉유 중

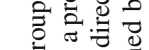

का on 0

올

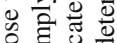

$0 .=$

. क

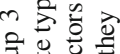

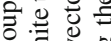

क力 ธิ

ชิ

च

○ $\Xi$

틀

กิ

$\approx$ Dิ

๙ิ

บิ ข ฮ 츨

ลิ

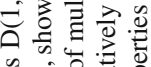

ปิ

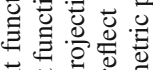

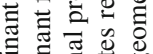

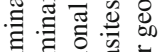

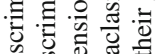

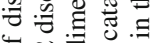

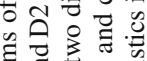

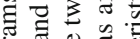

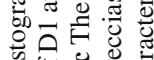

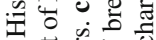

흔헨휴

$\infty$ 党

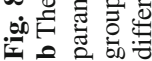


parameters are subordinate. As D2 function clearly separates cataclasites, this implies that the $A R$ has a strong role in their identification, together with the previously mentioned $P S D$ data.

The strong role of $A R$ values, especially in cataclasite samples, is probably connected to the propagation of the shear-parallel fractures. This has previously been reported as a specific sign of the evolving cataclastic texture, where the emerging orientation is usually marked by the direction of the elongated grains, resulting in grain shape-preferred orientation (GSPO) (Tanaka 1992). The reduction of $A R$ in the most deformed samples could be the result of the above mentioned rounding related to the gouge generation (chipping, abrasion, fracture propagation perpendicular to the shear plane), where wear of the clasts favours the formation of particles with a more isometric shape (Storti et al. 2007). The parameters not mentioned ( $D^{R}$ and the Conv) have only limited roles in both discriminant functions, which means that either they are not able to distinguish tectonites or their role can be expressed more properly by the combination of other parameters. Aside from their relatively weak role in the discrimination of different tectonites, it is necessary to detail their possible tendencies in a few words.

According to the earlier studies (e.g. Jébrak 1997), there is a good correlation between $D^{R}$ dimensions and the intensity of the chemical alteration processes. In this case, from the micro-scale samples-by the $D^{R}$ results-the breccias suffered the strongest fluid-rock interaction, while the fault gouges - with the transitional values of cataclasites-show the lowest $D^{R}$ dimensions. The most intensely deformed fault gouge clasts, which are mainly composed of monocrystalline quartz, seemingly do not favour strong fluid-rock interactions, which is in contrast to the less deformed particles. The changes in Conv data do not/only slightly correlate with lithological types. These results imply that the chemical resistivity of the clasts increases in parallel with the deformation.

The extremely different values of meso- and micro-scale $D^{R}$ data raise the question about their possibly distinct origin. According to Lalonde et al. (2010), these two, strongly dissonant groups of $D^{R}$ dimensions can be derived from the action of different reactions, namely, the diffusion limited-regime and the kinetic regime, respectively. The diffusion limited-regime acts at a thin section scale, while the scale kinetic regime is more characteristic in core sample clasts (Jébrak 1997; Lalonde et al. 2010). The diffusion-limited regime is governed by the diffusion rate of the reactants, and only the most exposed parts of the solid (such as the corners) are reached by these reactants. This regime therefore leads to a relative smoothing of the external grain surfaces (Lalonde et al. 2010), especially in thin section scale samples, where single mineral particles are abundant. The kinetic regime is characterised by a consumption rate that is limited only by the chemical reaction rate. The concentration of the reactants is the same everywhere and the external surface of the solid is totally exposed to the reactants, leading to a progressive increase in the clast-complexity (Lalonde et al. 2010); this is visible in the rock-fragment dominant meso-scale samples.

In the following, the relative positions of the samples in the theoretical six-dimensional space of the measured geometric parameters were computed using the multidimensionalscaling algorithm in order to reveal their possible relationships (Fig. 8c). The calculated twodimensional projection clearly illustrates the relative spatial position, as well as evolution trends of the different tectonites. Both breccias and cataclasites reflect significant variability along the same direction. This direction is defined by the projected axes of $A R, P S D$ and Angle parameters, while other parameters have close to constant values or reflect relatively low changes along this direction. In contrast, fault gouge samples change along a direction almost perpendicular to the previous orientation, which is marked by the theoretical directions of $P S D$ and Circ values. This implies that the groups of breccias and cataclasites are defined 


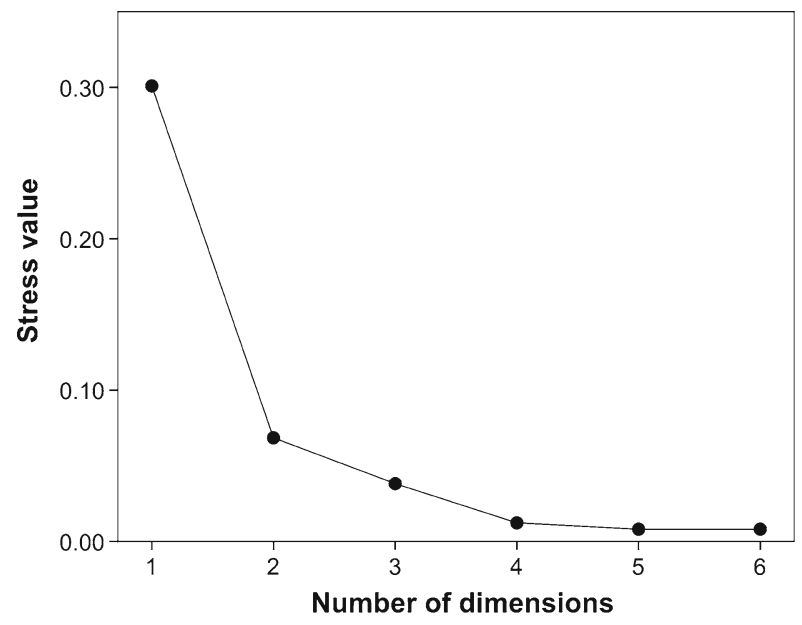

Fig. 9 Scree plot of the multidimensional-scaling. The plot of the stress values and the dimensions imply that the addition of the first four dimension (with PSD, Angle, AR, and Circ parameters) add significantly to the model

by the same parameters, while the fault gouges show characteristically different evolution, which is visible in their different determining parameters.

The scree plot resulting from the multidimensional-scaling is illustrated on Fig. 9. Important feature of the plot is the steep decreasing in stress values during the addition of the first four dimensions. The process is followed by shallowing of the slope, which indicates the four dimensional solution of the multidimensional-scaling. This flat stage reveal that the effect of the fifth and sixth dimension is negligible as these provide only minimal improvement to the validity of the model (e.g. decreasing in the stress value). All these observations on the position and structure of the axes point out that the relative position of the samples can be defined by their AR, PSD, Circ and Angle values.

By the statistical evaluation of the three tectonite groups and the marking of important distinctive geometric parameters, the pathway of deformation and the related mechanisms can also be identified (Fig. 10). Directions of progressive fault rock evolution are inferred from the microstructurally defined order in the degree of the fragmentation of micro-scale samples. The initial deformation is marked by the progressive evolution of breccias, which is observable most characteristically by the increasing $A R$ values coupled with chaotic fabric giving a typical weakly disaggregated, coarse fault breccia texture. This can mark the mechanism of the initial fragmentation, which is primarily visible in their increasing elongation (along Process 1). The slightly decreasing $P S D$ values along the Process 1 imply that this parameter has only a subordinate role in the evolution of fault breccias. The fragmentation-marked by the $P S D$ - possibly becomes an important factor in the advanced stages of deformation. The onset of comminution and cataclastic deformation is marked by the appearance of increasing GSPO with clast elongation as a result of shear-parallel fracture-propagation. The result of multidimensional-scaling demonstrated that the increasing intensity of cataclastic flow (comminution, clast rotation, micro-fracturing and sliding along these fracture planes with locally anastomising texture (Hirono et al. 2008)) leads to a more oriented structure, marked by a decrease of the Angle values. Prevailing surface abrasion, chipping and grinding in the cataclasites tend to decrease the $A R$ values as a result of the presence of fractures perpendicular to the shear plane, which is visible in the parameter changes along Process 2 . This process trans- 


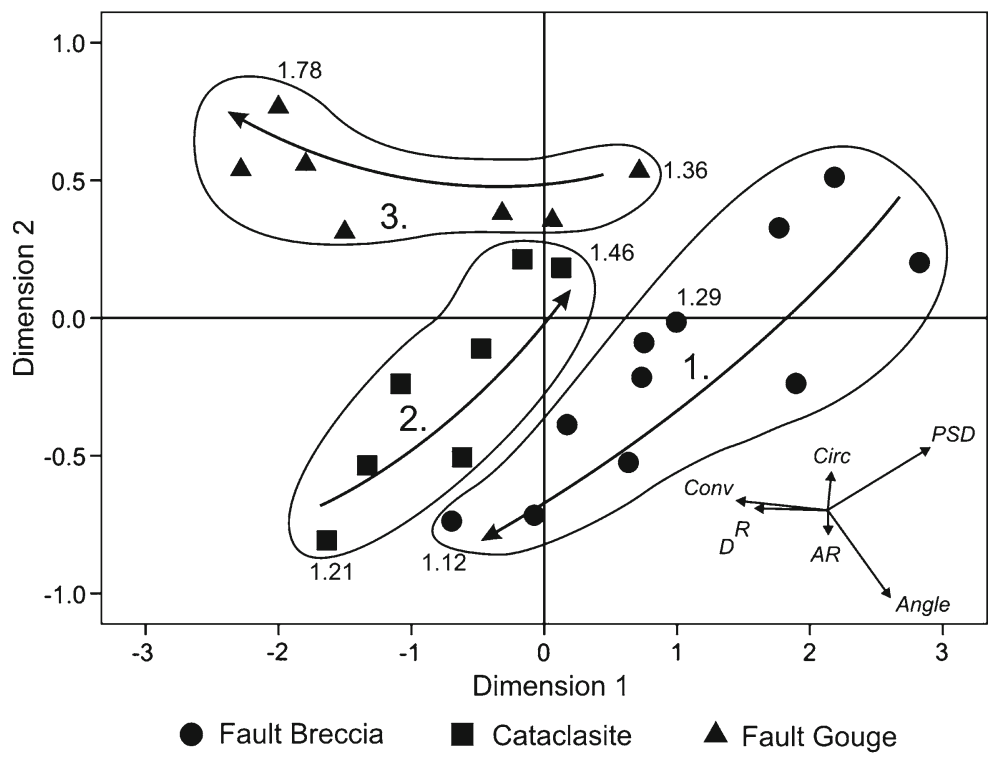

Fig. 10 Possible evolution of different tectonites by their geometric parameters. Process 1 initial fragmentation of the breccias, 2 onset of cataclastic flow and comminution, 3 gouge forming by chipping, abrasion and rounding of particles and intensive grain size reduction. Numbers denote the extreme PSD values for each group

forms to fault gouge formation (Process 3) through the development of a strongly oriented structure with progressively increasing $P S D$ values, the dominantly rounded particles and the evolved GSPO. The totally comminuted texture of fault gouges reflects a distinct group with regard to their geometric parameters in comparison with the two earlier groups: according to the statistical evaluation of PIA data, the breccias and the cataclasites have strong connection in the evolution of their geometric properties (although there are parameters which are able to distinguish them), while fault gouges follow clearly different trends in the clast geometric data.

\subsection{Possible effects of clast geometry on hydraulic properties}

The observed petrographic and clast geometric parameters indicate that there is presumably a strong connection between particle size/shape and the fluid flow properties of fault zones.

Angular particles inhibit rolling and mainly deform by stick-slip motion, fragmentation, and dilatation (Blenkinsop 1991), resulting in weakly disaggregated angular rock-fragments. According to Storti et al. (2007), the abundance of coarse, angular clasts may maintain enhanced transmissibility by protecting the pore spaces between the fragments. In contrast, the rounded fault gouge particles resulting from comminution accommodate shear by the low-friction mechanism of rolling (Hecht 2000; Storti et al. 2007). This mechanism results in stable-sliding tendencies in these localised zones, which implies a fault weakening behaviour and-via positive feedback between the gouge generation and the strain localisation-an increasing concentration of displacement.

From the perspective of reservoir properties, the fluid flow behaviour of the examined fault zone is under the control of gouge-bearing fault core layers. The strain localisation can protect the elevated porosity and permeability of the coarse breccia-bearing zones compared 
to the undeformed protolith. In contrast, thin gouge layers usually have extremely weak fluid flow properties, which can result in the compartmentalisation of the hydraulic regimes in the fault zone (Caine et al. 1996).

\section{Conclusions}

According to the measured parameters (PSD, $D^{R}, A R$, Circ, Conv, and Angle), their proper usage is able to determine the typical geometric features of different tectonites. In order to distinguish fault rocks based on their clast geometric attributes and to reveal the main mechanisms of deformation, multivariate statistical methods were applied. The discriminant function analysis defined the appropriate combination of parameters for the separation of different tectonites and pointed out the relatively similar geometric features of fault breccias and cataclasites in contrast to the significantly different characteristics of fault gouges. The multidimensional scaling demonstrated a three-phase evolution of the analysed brittle and semi-brittle tectonites, reflecting strongly distinct deformational pathways in each stage. The importance of parameters according to their weight in the applied functions were the following, in descending order: PSD, Angle, AR, and Circ. Application of the above methods separates the fault rocks with diverse petrophysical properties and also provides an opportunity to extend microstructural information gained at borecore-scale to spatial data, which can provide answers on the overall behaviour of the fault zone.

Acknowledgments We thank MOL Hungarian Oil and Gas Company for providing the samples and the financial support of this research. We are grateful to Gyula Maros (Hungarian Geological and Geophysical Institute) for his help in the use of ImaGeo corescanner. English was corrected by Proof-Reading-Service.com.

\section{References}

Antonellini M, Aydin A (1995) Effect of faulting on fluid flow in porous sandstones: geometry and spatial distribution. Am Assoc Pet Geol Bull 79:642-671

Barnett W (2004) Subsidence breccias in kimberlite pipes—an application of fractal analysis. Lithos 76:299_ 316

Ben-Zion Y, Sammis CG (2003) Characterization of fault zones. Pure Appl Geophys 160:677-715

Bérubé D, Jébrak M (1999) High precision boundary fractal analysis for shape characterization. Comput Geosci 25:1059-1071

Biegel RL, Sammis CG, Dieterich JH (1989) The frictional properties of a simulated gouge having a fractal particle distribution. J Struct Geol 11:827-846

Billi A (2007) On the extent of size range and power law scaling for particles on natural carbonate fault cores. J Struct Geol 20:1512-1521

Billi A, Storti F (2004) Fractal distribution of particle size in carbonate rocks from the core of a regional strike-slip fault zone. Tectonophysics 384:115-128

Billi A, Salvini F, Storti F (2003) The damage zone-fault core transition in carbonate rocks: implication for fault growth, structure and permeability. J Struct Geol 25:1779-1794

Bistacchi A, Massironi M, Menegon L (2010) Three-dimensional characterization of a crustal-scale fault zone: the Pusteria and Sprechenstein fault system (Eastern Alps). J Struct Geol 32:2022-2041

Blenkinsop TG (1991) Cataclasis and processes of particle size reduction. Pure Appl Geophys 136:59-86

Brodie K, Fettes D, Harte B (2007) Structural terms including fault rock terms. In: Fettes D, Desmonds J (eds) Metamorphic rocks: a classification and glossary of terms. Cambride University Press, Cambride, pp 24-31

Caine JS, Evans JP, Forster CB (1996) Fault zone architecture and permeability structure. Geology 24:10251028

Cattell RB (1966) The scree test for the number of factors. Multivariate Behav Res 1:245-276

Chester FM, Friedman M, Logan JM (1985) Foliated cataclasites. Tectonophysics 111:139-146 
Cladouhos TT (1999) Shape preferred orientations of survivor grains in fault gouge. J Struct Geol 21:419-436

Clark C, James P (2003) Hydrothermal brecciation due to fluid pressure fluctuations: examples from Olary Domain, South west Australia. Tectonophysics 366:187-206

Engelder JT (1974) Cataclasis and the generation of fault gouge. Geol Soc Am Bull 85:1515-1522

Evans JP, Forster CB, Goddard JV (1997) Permeability of fault-related rocks and implications for fault-zone hydraulic structure. J Struct Geol 19:1393-1404

Faulkner DR, Jackson CAL, Lunn RJ, Schlische RW, Shipton ZK, Wibberley CAJ, Withjack MO (2010) A review of recent developments concerning the structure, mechanics and fluid flow properties of fault zones. J Struct Geol 32:1557-1575

Fossen H, Schultz RA, Shipton ZK, Mair K (2007) Deformation bands in sandstone: a review. J Geol Soc 164:755-769

Hausegger S, Kurz W, Rabitsch R, Kiechl E, Brosh FJ (2010) Analysis of the internal structure of a carbonate damage zone: implications for the mechanisms of fault breccia formation and fluid flow. J Geol Soc 32:1349-1362

Hecht CA (2000) Appolonian packing and shape of grains improving geomechanical properties in engineering geology. Pure Appl Geophys 157:487-504

Heilbronner R, Keulen N (2006) Grain size an grain shape analysis of fault rocks. Tectonophysics 427:199-216

Hirono T, Sakaguchi M, Otsuki K, Sone H, Fujimoto K, Mishima T, Lin W, Tanikawa W, Tanimizu M, Soh W, Yeh E, Song S (2008) Characterization of slip zone associated with the 1999 Taiwan Chi-Chi earthquake: $\mathrm{X}$-ray CT image analyses and microstructural observations of the Taiwan Chelungpu fault. Tectonophysics 449:63-84

Jébrak M (1997) Hydrothermal breccias in vein-type ore deposits: a review of mechanisms, morphology and size distribution. Ore Geol Rev 12:111-134

Jeppson TN, Bradbury KK, Evans JP (2010) Geophysical properties within the San Andreas Fault Zone at the San Andreas Fault Observatory at Depth and their relationships to rock properties and fault zone structure. J Geophys Res 115:B12423. doi:10.1029/2010JB007563

Kaye BH (1989) A random walk through fractal dimension. VCH Publishers, New York

Keulen N, Heilbronner R, Stünitz H, Boullier AM, Ito H (2007) Grain size distributions of fault rocks: a comparison between experimentally and naturally deformed granitoids. J Struct Geol 29:1282-1300

Lalonde M, Tremblay G, Jébrak M (2010) A Cellular Automata Breccia Simulator (CABS) and its application to rounding in hydrothermal breccias. Comput Geosci 36:827-838

Laznicka P (1988) Breccias and coarse fragmentites. Petrology, environments, associations, ores. Dev Econ Geol 25:842

Lee H, Kim H (2005) Comparison of structural features of the fault zone developed at different protoliths: crystalline rocks and mudrock. J Struct Geol 27:2099-2112

Lin A (1999) S-C cataclasite in granitic rock. Tectonophysics 304:257-273

Manzocchi T, Childs C, Walsh JJ (2010) Faults and fault properties in hydrocarbon flow models. Geofluids 10:94-113

Maros Gy, Pásztor Sz (2001) New and oriented core evaluation method: ImaGeo. Eur Geol 12:40-43

Mort K, Woodcock NH (2008) Quantifying fault breccia geometry: Dent Fault, NW England. Journal of Structural Geology 30:701-709

Nelson RA (2001) Geologic analysis of naturally fractured reservoirs, 2nd edn. Gulf Publishing Company Book Division, Houston

P'an CH (1982) Petroleum in basement rocks. Am Assoc Pet Geol Bull 66:1597-1643

Passchier CW, Trouw RAJ (2005) Microtectonics. Springer, New York

Petford N, McCaffrey KJW (2003) Hydrocarbons in crystalline rocks. Geol Soc Spec Publ 214:1-5

Posgay K, Bodoky T, Hegedűs E, Kovácsvölgyi S, Lenkey L, Szafián P, Takács E, Timár Z, Varga G (1995) Asthenospheric structure beneath a Neogene basin in southeast Hungary. In: Cloetingh S, D'Argenio B, Catalano R, Horváth F, Sassi W (eds) Interplay of extension and compression in basin formation. Tectonophysics, vol 252, pp 467-484

Sammis CG, Osborne RH, Anderson JL, Banerdt M, White P (1986) Self-similar cataclasis in the formation of fault gouge. Pure Appl Geophys 124:54-77

Sammis CG, King G, Biegel R (1987) The kinematics of gouge deformation. Pure Appl Geophys 125:777-812

Schubert F, Diamond LW, Tóth MT (2007) Fluid-inclusion evidence of petroleum migration through a buried metamorphic dome in the Pannonian Basin, Hungary. Chem Geol 244:357-381

Sibson RH (1977) Fault rocks and fault mechanisms. J Geol Soc 133:191-213

Sibson RH (1986) Brecciation processes in fault zones: inferences from earthquake rupturing. Pure Appl Geophys 124:159-174

Storti F, Balsamo F (2010) Impact of ephemeral cataclastic fabrics on laser diffraction particle size distribution analysis in loose carbonate fault breccia. J Struct Geol 32:507-522 
Storti F, Billi A, Salvini F (2003) Particle size distributions in natural carbonate fault rocks: insights for non-self similar cataclasis. Earth Planet Sci Lett 206:173-186

Storti F, Balsamo F, Salvini F (2007) Particle shape evolution in natural carbonate granular wear material. Terra Nova 19:344-352

Stünitz H, Keulen N, Hirose T, Heilbronner R (2010) Grain size distribution and microstructures of experimentally sheared granitoid gouge at coseismic slip rates-crtieria to distinguish seismic and aseismic faults? J Struct Geol 32:59-69

Tanaka H (1992) Cataclastic lineations. J Struct Geol 14:1239-1252

Tari G, Dövényi P, Dunkl I, Horváth F, Lenkey L, Stefanescu M, Szafián P, Tóth T (1999) Lithospheric structure of the Pannonian basin derived from seismic, gravity and geothermal data. In: Durand B, Jolivet L, Horváth F, Séranne M (eds) The Mediterranean basins: tertiary extension within the Alpine orogen. Special Publications, vol 156. Geological Society, London, pp 215-250

Tóth MT (2008) Repedezett, metamorf fluidumtárolók az Alföld aljzatában. Academic Doctoral Thesis (in Hungarian)

Tóth MT, Redlerné TM, Kummer I (2009) Structural evolution of Szeghalom Dome on the basis of petrological and seismic data. Hung Geophys 29:143-151 (in Hungarian with English abstract)

Turcotte DL (1986) Fractals and fragmentation. J Geophys Res 91:1921-1926

Wibberley CAJ, Shimamoto T (2003) Internal structure and permeability of major strike-slip fault zones: the Median Tectonic Line in Mie Prefecture, Southwest Japan. J Struct Geol 25:59-78

Woodcock NH, Mort K (2008) Classification of fault breccias and related fault rocks. Geol Mag 145:435-440 